\title{
Rapid habituation of the cold shock response
}

\author{
Clare M Eglin", George Butt, Stephen Howden, Thomas Nash, Joseph Costello \\ From 15th International Conference on Environmental Ergonomics (ICEE XV) \\ Portsmouth, UK. 28 June - 3 July 2015
}

\section{Introduction}

Sudden immersion into cold water initiates a series of cardio-respiratory responses collectively known as the cold shock response (CSR) which may increase an individual's risk of drowning. The CSR is stimulated by a rapid fall in skin temperature and includes tachycardia, a reflex inspiratory gasp followed by uncontrollable hyperventilation. Repeated cold water immersions conducted over several days have been shown to reduce the magnitude of the CSR [1]. This study investigated whether an habituation could be achieved in a couple of hours; it was hypothesised that following this rapid habituation the CSR would be reduced on a subsequent cold water immersion.

\section{Methods}

Nine healthy males (mean [SD] age 21[2] years, height $179[7] \mathrm{cm}$, mass $76[13] \mathrm{kg}$ ) with no previous cold water exposure, undertook two head-out immersions into stirred water at $15{ }^{\circ} \mathrm{C}$ for 5 minutes wearing swimming trunks. These immersions were undertaken one week apart at the same time of day (IMM1 and IMM7). One or two days after IMM1, participants undertook five, 3 -minute, head-out immersions into $15{ }^{\circ} \mathrm{C}$ water over a period of 55 to $120 \mathrm{~min}$. In between each habituation immersion they rewarmed in a bath at $38^{\circ} \mathrm{C}$ for 3 minutes and the next immersion occurred approximately 10 minutes later. Heart rate $\left(\mathrm{f}_{\mathrm{C}}\right)$, respiratory frequency $\left(\mathrm{f}_{\mathrm{R}}\right)$, tidal volume $\left(\mathrm{V}_{\mathrm{T}}\right)$ and inspiratory minute volume $\left(\mathrm{V}_{\mathrm{I}}\right)$ were measured prior to and during each immersion. Data for IMM1 and IMM7 were averaged over the following time periods: $0-30,30-60$, and $60-300 \mathrm{~s}$ and are presented as mean[sd].

\section{Results}

$\mathrm{f}_{\mathrm{C}}$ was reduced throughout IMM7 compared to IMM1 (0-30 s: $117[21]$ v 106[14] bpm; 30-60 s: 110 [21] v 86[19] bpm; 60-300 s: 90[18] v 78[17] bpm; all $\mathrm{P}<0.05)$. $\mathrm{V}_{\mathrm{I}}$ was attenuated in IMM7 compared to IMM1 over the first minute of immersion $(0-30 \mathrm{~s}: 61.3[7.5] \mathrm{v} 52.5[12.1] \mathrm{L}$. $\mathrm{min}^{-1}$; 30-60s: 50.8[13.5] v 40.5[13.6] L. $\left.\mathrm{min}^{-1} ; \mathrm{P}<0.05\right)$ whereas $f_{R}$ was only reduced in the first $30 \mathrm{~s}$ from $37(11)$ to 29(9) breaths. $\mathrm{min}^{-1}(\mathrm{P}<0.05)$. The inspiratory gasp observed within the first $10 \mathrm{~s}$ of immersion was similar in IMM1 and IMM7 (2.44[0.62] v 2.71[0.64] L, p > 0.05) as was $V_{\mathrm{T}}$ throughout the immersions.

\section{Discussion}

Repeated immersions conducted over a short time period (1-2 hours) on the same day resulted in a decrease in $f_{C}, f_{R}$ and $V_{I}$ during the first $30 \mathrm{~s}$ of immersion. This may reduce the risk of drowning by attenuating ventilation and thus the risk of water aspiration as well as lowering $\mathrm{f}_{\mathrm{C}}$ and therefore cardiac strain on immersion. No reduction in either $V_{T}$ or the inspiratory gasp was observed, probably because $f_{R}$ decreased giving a longer duration for each inspiration. As previous studies [2] have indicated that $f_{R}$ is a better indicator of respiratory drive than $\mathrm{V}_{\mathrm{T}}$ during the CSR, the current findings suggest that respiratory drive was reduced following the rapid habituation protocol.

\section{Conclusion}

Rapid habituation to the CSR is possible and may provide a practical and inexpensive method of protection against drowning for individuals who are deployed at short notice to situations where they are at risk of accidental cold water immersion.

\section{Published: 14 September 2015}

\section{References \\ 1. Tipton, et al: Temperature dependence of habituation of the initial responses to cold water immersion. Eur J Appl Physiol 1998, 78:253-57.}

\footnotetext{
* Correspondence: clare.eglin@port.ac.uk

Extreme Environments Laboratory, Department of Sport and Exercise Science, University of Portsmouth, Portsmouth, UK
} 
2. Tipton, et al: Human initial responses to immersion in cold water at three temperatures and after hyperventilation. J Appl Physiol 1991, 70:317-322.

doi:10.1186/2046-7648-4-S1-A38

Cite this article as: Eglin et al:: Rapid habituation of the cold shock response. Extreme Physiology \& Medicine 2015 4(Suppl 1):A38.

Submit your next manuscript to BioMed Central and take full advantage of:

- Convenient online submission

- Thorough peer review

- No space constraints or color figure charges

- Immediate publication on acceptance

- Inclusion in PubMed, CAS, Scopus and Google Scholar

- Research which is freely available for redistribution 